\title{
A Comparison of Blood Amino Acid Concentrations Following Ingestion of Rice and Whey Protein Isolate: A Double-Blind Crossover Study Purpura $\mathrm{M}^{* 1}$, Lowery $\mathrm{RP}^{2}$, Joy JM${ }^{2}$, De Souza EO ${ }^{2}$, Kalman $\mathrm{DS}^{3}$, Jäger $\mathrm{R}^{1}$ and Wilson $\mathrm{JM}^{2}$
}

${ }^{1}$ Increnovo LLC, 2138 E Lafayette Pl, Milwaukee, WI 53202, USA

${ }^{2}$ Department of Health Sciences and Human Performance, the University of Tampa, USA

${ }^{3}$ Department of Nutrition and Endocrinology, Miami Research Associates, Miami, FL, USA

${ }^{*}$ Corresponding author: Purpura M, Increnovo LLC, 2138 E Lafayette Pl, Milwaukee, USA

Citation: Purpura M, Lowery RP, Joy JM, De Souza EO, Kalman DS, et al. (2014) A Comparison of Blood Amino Acid Concentrations Following Ingestion of Rice and Whey Protein Isolate: A Double-Blind Crossover Study. J Nutr Health Sci 1(3): 306. doi: 10.15744/2393-9060.1.306

Received Date: August 07, 2014 Accepted Date: November 03, 2014 Published Date: November 06, 2014

\begin{abstract}
Background: This study investigated comparative concentrations of individual amino acids, total amino acids (TAA), non-essential amino acids (NEA) and essential amino acids (EAA) in the blood after the administration of Rice Protein Isolate (RPI) compared to Whey Protein Isolate (WPI).

Methods: After a 12 hour overnight fast, 10 trained male subjects were randomly assigned to receive either 48 grams of RPI or WPI in a double-blind, crossover design, separated by a washout period of 7 days. Blood draws were taken immediately prior to and at 1 , 2, 3, and 4 hours following consumption of WPI or RPI. Pharmacokinetic parameters of plasma concentrations of amino acids were analyzed by a repeated measure ANOVA. $\mathrm{AUC}_{0-1}$, and $\mathrm{C}_{\max }$ were analyzed by $\mathrm{t}$-tests.

Results: WPI and RPI showed a significant difference between $\mathrm{T}_{\max }$ for essential amino acids (EAA: RPI $87 \pm 7$ min, WPI $67 \pm 4$ min, $\mathrm{p}=0.03$ ), non-essential amino acids (NEA: RPI $97 \pm 4 \mathrm{~min}$, WPI $71 \pm 5 \mathrm{~min}, \mathrm{p}<0.001$ ), and total amino acids (TA: RPI $93 \pm 4 \mathrm{~min}$, WPI $69 \pm 3 \mathrm{~min}, \mathrm{p}<0.001$ ), however no significant differences were detected for AUC (EAA: RPI $649.5 \pm 140.9 \mathrm{nmol} / \mathrm{ml}, \mathrm{WPI} 754.2 \pm$ $170.0 \mathrm{nmol} / \mathrm{ml}, \mathrm{p}=0.64$; NEA: RPI $592.7 \pm 118.2 \mathrm{nmol} / \mathrm{ml}$, WPI $592.7 \pm 121.2 \mathrm{nmol} / \mathrm{ml}, \mathrm{p}=0.98$; TAA: RPI $615.9 \pm 88.6 \mathrm{nmol} / \mathrm{ml}, \mathrm{WPI}$ $661.1 \pm 98.7 \mathrm{nmol} / \mathrm{ml}, \mathrm{p}=0.74)$, and neither for $\mathrm{C}_{\max }$ (EAA: RPI $176.1 \pm 37.5 \mathrm{nmol} / \mathrm{ml}$, WPI $229.5 \pm 51.2 \mathrm{nmol} / \mathrm{ml}, \mathrm{p}=0.41$; NEA: RPI $160.0 \pm 31.1 \mathrm{nmol} / \mathrm{ml}$, WPI $178.4 \pm 34.0 \mathrm{nmol} / \mathrm{ml}, \mathrm{p}=0.69$; TA: RPI $166.6 \pm 23.4 \mathrm{nmol} / \mathrm{ml}$, WPI $199.3 \pm 28.8 \mathrm{nmol} / \mathrm{ml}, \mathrm{p}=0.38)$. On an individual amino acid basis, WPI was faster or equal for all amino acids with the excpetion of leucine, which reached $\mathrm{C}_{\max }$ faster in the RPI group.

Conclusion: While RPI elicited a 6.8\% lower total amino acid concentration in the blood based on AUC compared to WPI, the difference was not statistically significant. Future research should investigate additional time points and stable isotope labels to study digestion and effect on whole body net protein synthesis in relation to the used protein.
\end{abstract}

\section{Introduction}

Protein supplementation after resistance exercise increases muscle protein synthesis (MPS) rates and reduces muscle protein breakdown $[1,2]$. In this regard, competitive and recreational athletes habitually consume protein-containing supplements during and/or after exercise in order to augment gains in muscle mass accretion. In addition, athletes have the choice of a broad range of animal derived protein sources like whey, casein, egg, beef, and fish, or plant derived protein sources like soy, rice, pea, hemp, chia and flaxseed. The protein sources differ in numerous ways such as the presence of allergens (milk, soy), cholesterol, saturated fats, digestion rate (fast, intermittent, slow absorption of amino acids), or the relative amount of individual amino acids. Compared to animal protein sources, plant protein sources, with the exception of soy protein, are more often deficient in one or more essential amino acids resulting in being qualified as an incomplete protein source. However, this deficit can be overcome by blending different plant protein sources, e.g. pea (low in methionine and cysteine) and rice (low in lysine), or by incorporating grains and legumes in the athlete's diet [3]. Dietary protein sources are broken down in the gastrointestinal tract by digestive enzymes into the corresponding free amino acids and oligopeptides [4,5]. Nevertheless, the protein digestibility differs between protein sources with animal proteins (whey protein concentrate 100\% [6], casein 99\% [6]) generally being better absorbed than plant proteins (soy protein isolate $95 \%$ [6], pea $93.5 \%$ [7] or RPI 87\% [8]).

Out of a total of twenty amino acids, eleven are classified as non-essential amino acids (NEAA) as they can be produced by the human body. The remaining nine amino acids are classified as essential amino acids (EAA) as they must be provided exogenously through the diet [9]. Protein quality is among the greatest concerns for today's athletes and is generally defined as a proteins cap- 
acity to provide essential amino acids (EAA) to an individual [10,11]. Branched-chain Amino Acids (BCAA), isoleucine, valine, and leucine have been shown to stimulate muscle protein synthesis (MPS) at the same level as all nine EAA combined [12]. Leucine is the only BCAA that stimulates MPS alone [12,13]. Norton et al. suggest that leucine content is a direct indicator of protein quality as it relates to acute stimulation of MPS [14]. Therefore, leucine content of a protein should be emphasized when evaluating the quality of protein for athletes. Specifically whey protein is naturally rich in leucine (10-11\%), whereas plant proteins contain $6-8 \%$ of leucine.

Research on the physiological effects of rice protein has been limited due to the fact that the purification and enrichment of rice protein, resulting in highly concentrated RPI, has been a technical challenge since the early 90's [15]. RPI has been shown to display anti-atherogenic potential, which was tested in comparison to soya-protein isolate and casein, in apolipoprotein E-deficient mice [16]. Phytochemicals bound to RPI have also been reported to show in vitro antitumor activities in rats [17]. In addition, RPI has been demonstrated to improve lipid and glucose homeostasis in rats fed high fat/high cholesterol diets [18]. A recent study compared the consumption of $48 \mathrm{~g}$ of both WPI and RPI (isocaloric and isonitrogenous) after 8 weeks of non-linear periodized resistance training for the indices of body composition and exercise performance in resistance trained males [19]. The authors demonstrated that high-dose RPI supplementation decreased fat-mass and increased lean body mass, skeletal muscle hypertrophy, power and strength post resistance exercise comparable to WPI, indicating that potential differences in protein quality become less relevant if the protein is consumed in sufficient amounts.

Therefore, the current study investigated the effects of protein supplementation on concentrations of total amino acids (TAA), non-essential amino acids (NEA) and essential amino acids (EAA) in the blood after the administration of 48 grams of RPI in comparison to WPI in a crossover, double-blind design.

\section{Methods}

\section{Study Design}

A double blind, two-period, two-sequence, crossover study was performed to assess the amino acid concentration in the blood after the administration of RPI and WPI from a fasted condition in trained male athletes. Participants were randomly assigned to administer 48 grams of either RPI (Growing Naturals Rice Protein Isolate made with Oryzatein ${ }^{\circledR}$ rice protein, Axiom Foods, Oro Valley, AZ, Lot \#071612310) or WPI (Nutra Bio Whey Protein Isolate, Middlesex, NJ, Lot \#219253D). Prior to the study, the amino acid profile, crude protein content and moisture were analyzed by an independent third party lab (Eurofins Analytical Laboratories, Metairie, LA). On an as-is-basis, the test materials contained $6.64 \%$ (WPI) or $6.14 \%$ (RPI) moisture (air oven $130{ }^{\circ} \mathrm{C}$ method AOAC 945.39 ) and $79.9 \%$ (WPI) or 69.3\% (RPI) crude protein (combustion method AOAC 992.15). The amino acid profile of each formulation is displayed in Table 1.

The WPI and RPI supplements were matched to be isonitrogenous and isocaloric and were consumed as a liquid formulation by mixing the individual protein powder with $500 \mathrm{ml}$ of water. After a one-week washout period, the experiment was repeated with the subjects consuming the other formulation. The identity of the study proteins that were given to the participants remained unknown to both the participants and the researchers for the entirety of the study.

\section{Subjects}

Ten resistance trained male students currently enrolled at The University of Tampa volunteered for this study. The participants were $22.2 \pm 4.2$ years of age, had an average bodyweight of $77.4 \pm 0.6 \mathrm{~kg}$, and an average height of $176.8 \mathrm{~cm} \pm 8.6 \mathrm{~cm}$. No subject had any physical or medical health complications according to past health examinations and all subjects were non-smokers to be included in this study. Participants were required to abstain from consuming any protein supplements for one month prior and during the wash-out of seven days. The volunteers had to complete an overnight fast of 12 hours duration before the morning of the study. This study was approved by the Institutional Review Board at The University of Tampa and each participant had signed an informed consent before any study related procedures were performed.

\section{Measurement of Amino Acids}

The amino acids measured in the blood plasma consisted of the nine essential amino acids (histidine, isoleucine, leucine, lysine, methionine, phenylalanine, tryptophan, threonine, and valine), as well as thirteen non-essential amino acids (alanine, arginine, asparagine, aspartic acid, citrulline, cystine, glutamic acid, glutamine, glycine, ornithine, proline, serine, and tyrosine). Amino acid concentrations were measured in the blood plasma prior to the oral administration of RPI or WPI to establish baseline measurements. All amino acid concentrations were then tested by taking blood plasma samples at 1 hour, 2 hours, 3 hours, and 4 hours following either consumption of RPI or WPI protein supplements. The second period began after a seven day wash-out period and initial blood test was completed once again to reassess the concentration of each amino acid in the blood plasma prior to taking the protein supplement that the subject had not already consumed. Measurement of amino acid plasma concentrations were then done consecutively in the same manner as the previous week in the pattern of 1 hour, 2 hours, 3 hours, and 4 hours. 
Blood draws throughout the study were obtained via venipuncture after a 12-hour fast by a trained phlebotomist. Whole blood was collected and transferred into Becton Dickinson (BD) $8.5 \mathrm{ml}$ tubes (BD Vacutainer SST) for obtaining serum and plasma and subsequently centrifuged at $1,500 \mathrm{~g}$ for $15 \mathrm{~min}$ at $4{ }^{\circ} \mathrm{C}$. Resulting serum and plasma were then aliquoted and stored at $-80{ }^{\circ} \mathrm{C}$ until subsequent analyses.

Phenomenex EZ: fast amino acid analysis kits (Torrance, CA) were used for liquid chromatographic analysis of amino acids using mass spectrometry (LC/MS). The procedure consisted of solid phase extraction of $25 \mu$ lof plasma by a sorbent tip attached to a syringe with an eluting solvent (a 3:2 mixture of sodium hydroxide with $77 \%$ n-propanol, and $23 \%$ 3-picoline). The free amino acids were then derivatized by adding a mixture of $17.4 \%$ propyl chloroformate, $11 \%$ isooctane, and $71.6 \%$ chloroform. The resulting mixture was vortexed and allowed to sit at room temperature for $1 \mathrm{~min}$, followed by liquid-liquid extraction with isooctane. $50 \mu \mathrm{l}$ of the organic layer was removed, dried under nitrogen gas, and suspended in the HPLC run solvent before being injected into the LC/MS. Chromatographic separation of the derivatized amino acids was conducted on an EZ: fast amino acid analysis-mass spectrometry column $(250 \times 2.0 \mathrm{~mm}$ i.d., $4 \mu \mathrm{m})$ using a Agilent 6460 triple quadrupole LC/MS system (Santa Clara, CA). $10 \mathrm{mM}$ ammonium formate in water (mobile phase A) and $10 \mathrm{mM}$ ammonium formate in methanol (mobile phase B) were used as solvent system with gradient conditions of $68 \%$ B (0 minutes) and $83 \%$ B (13 minutes) and a flow rate of $0.25 \mathrm{ml} / \mathrm{min}$. Amino acids and internal standard data were collected using the Dynamic MRM mode using Mass Hunter acquisition software (Agilent). Mass Hunter Quantitation software (Agilent) was used to quantitate the unknown plasma samples based on linear standard curves.

\section{Data Analysis}

A repeated measure ANOVA was performed to test differences in the plasma concentrations for all 22 amino acids. The area under the concentration vs. time curve (AUC) was calculated using the linear trapezoidal rule from time zero until the last time point of sampling $\mathrm{t}\left(\mathrm{AUC}_{0 \mathrm{t}}\right) \cdot \mathrm{C}_{\min }$ and $\mathrm{C}_{\max }$ were defined as the minimum and maximum observed concentrations, respectively. $\mathrm{t}_{\max }$ was the time at which $\mathrm{C}_{\max }$ was reached. AUC of the five conditions were compared and analyzed by paired-samples t-tests. A P-value $<0.05$ was considered statistically significant. Analyses were performed with the SPSS software package version 16.0 for Windows. Results are expressed as mean \pm standard error $(\mathrm{SE})$.

\section{Results}

There were significant differences between WPI and RPI for $\mathrm{T}_{\max }$ for EAA, NEAA, and TAA, however, no significant differences were detected for AUC and $\mathrm{C}_{\max }$ (Table 1) (Figure 1, 2 and 3).

\begin{tabular}{|c|c|c|}
\hline Amino Acid [mg/g of Protein] & WPI & RPI \\
\hline Alanine & 47 & 40 \\
\hline Arginine & 20 & 57 \\
\hline Aspartic Acid & 100 & 64 \\
\hline Cystine & 21 & 15 \\
\hline Glutamic Acid & 163 & 129 \\
\hline Glycine & 16 & 32 \\
\hline Histidine & 15 & 16 \\
\hline Isoleucine & 60 & 30 \\
\hline Leucine & 98 & 59 \\
\hline Lysine & 87 & 23 \\
\hline Methionine & 20 & 21 \\
\hline Phenylalanine & 28 & 39 \\
\hline Proline & 55 & 34 \\
\hline Serine & 47 & 37 \\
\hline Threonine & 65 & 26 \\
\hline Tryptophan & 19 & 10 \\
\hline Tyrosine & 27 & 35 \\
\hline Valine & 55 & 43 \\
\hline
\end{tabular}

Table 1: Amino acid profile of the study materials [19] 


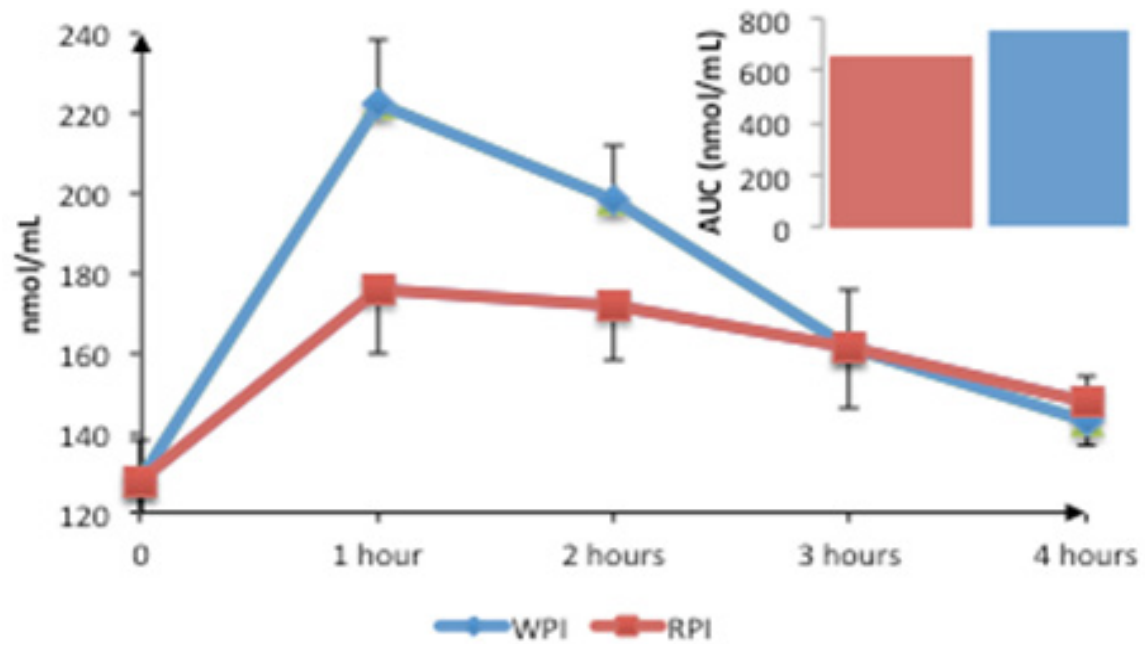

Figure 1: EAA Time Curve and AUC

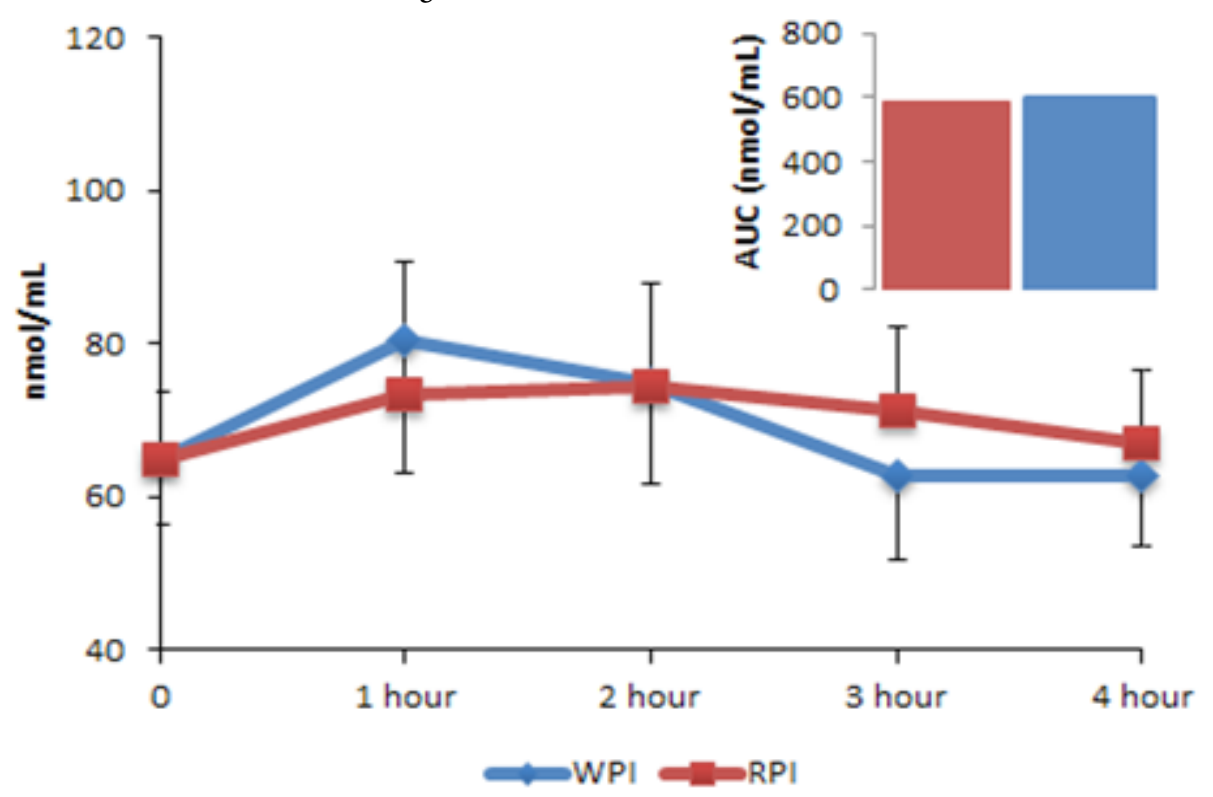

Figure 2: NEAA Time Curve and AUC.

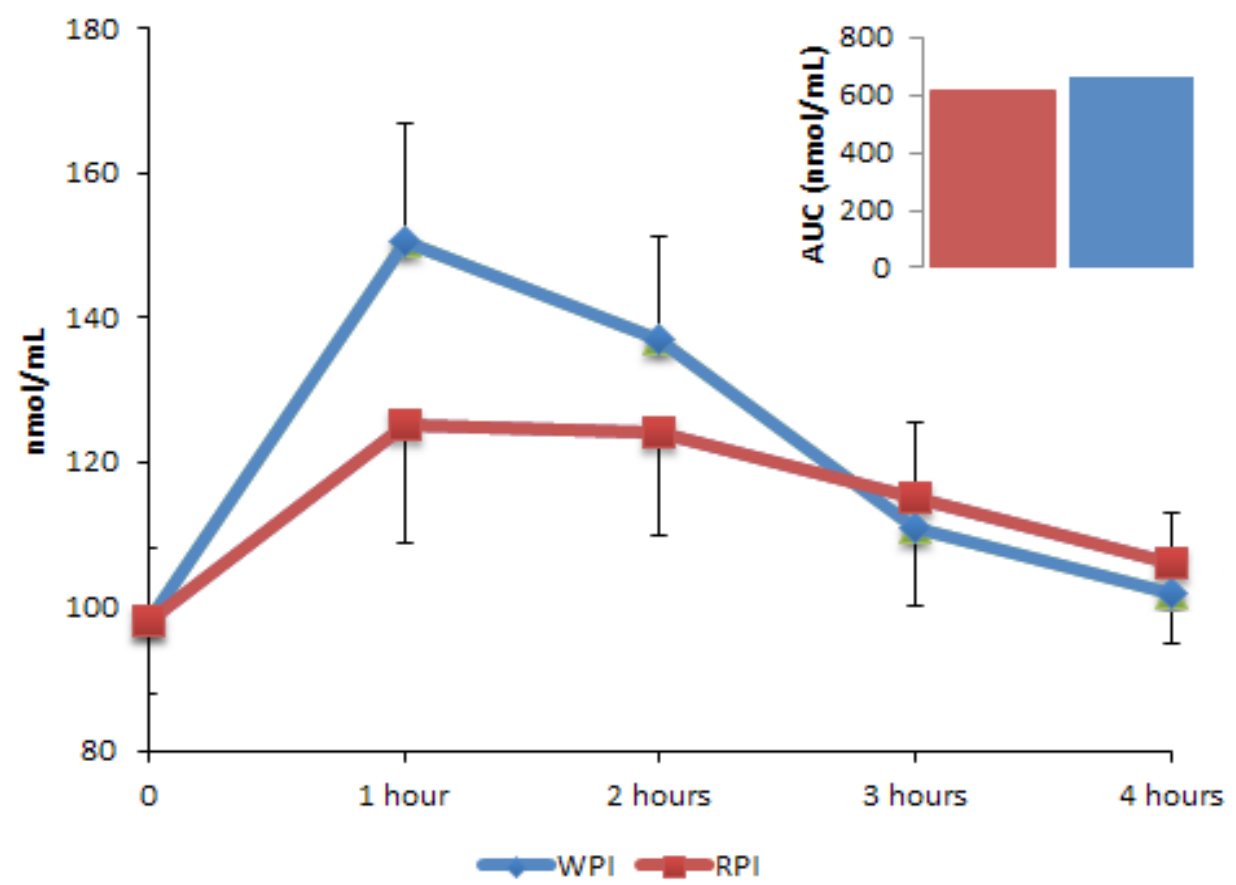

Figure 3: TAA Time Curve and AUC 
On an individual amino acid basis, WPI and RPI showed bioequivalency (0.80-1.25 of the geometric mean ratio (GMR)) for AUC and $\mathrm{C}_{\max }$ for all amino acids with the exception of cystine, isoleucine, leucine, lysine, and threonine, in which WPI demonstrated significantly higher values than RPI. $\mathrm{T}_{\max }$ occurred rapidly for WPI, indicative of a fast absorption rate, while $\mathrm{T}_{\max }$ for RPI occurred moderately fast, but slower than WPI for absorption rate for histidine, phenylalanine, threonine, asparagine, glutamic acid, glycine, ornithine, proline, and serine, suggesting that RPI is an intermediate protein (Table 2, 3 and 4).

\begin{tabular}{|c|c|c|c|}
\hline & Rice & Whey & P-Value \\
\hline \multicolumn{4}{|c|}{ EAA } \\
\hline $\mathrm{AUC}[\mathrm{nmol} / \mathrm{ml}]$ & $649.5 \pm 140.9$ & $754.2 \pm 169.9$ & 0.64 \\
\hline $\mathrm{C}_{\max }[\mathrm{nmol} / \mathrm{ml}]$ & $176.1 \pm 37.6$ & $229.5 \pm 51.2$ & 0.41 \\
\hline $\mathrm{T}_{\max }[\mathrm{min}]$ & $87 \pm 7$ & $67 \pm 4$ & ${ }^{*} 0.03$ \\
\hline \multicolumn{4}{|c|}{ NEAA } \\
\hline $\mathrm{AUC}[\mathrm{nmol} / \mathrm{ml}]$ & $592.7 \pm 118.2$ & $596.6 \pm 121.2$ & 0.98 \\
\hline $\mathrm{C}_{\max }[\mathrm{nmol} / \mathrm{ml}]$ & $160.0 \pm 31.1$ & $178.4 \pm 34.0$ & 0.69 \\
\hline $\mathrm{T}_{\max }[\mathrm{min}]$ & $97 \pm 4$ & $69 \pm 3$ & ${ }^{\star} 0.00$ \\
\hline \multicolumn{4}{|c|}{ TAA } \\
\hline $\mathrm{AUC}[\mathrm{nmol} / \mathrm{ml}]$ & $615.9 \pm 88.6$ & $661.1 \pm 98.7$ & 0.74 \\
\hline $\mathrm{C}_{\max }[\mathrm{nmol} / \mathrm{ml}]$ & $166.6 \pm 23.4$ & $199.3 \pm 28.8$ & 0.39 \\
\hline $\mathrm{T}_{\max }[\mathrm{min}]$ & $93 \pm 4$ & $69 \pm 3$ & ${ }^{\star} 0.00$ \\
\hline
\end{tabular}

Table 2: Cumulative Bioavailability of Essential and Non-Essential Amino Acids. Data expressed as Geometric Mean \pm SEM. ${ }^{\star}$ Represents significance at an alpha of 0.05 .

\begin{tabular}{|c|c|c|c|c|}
\hline Amino Acid & RPI & WPI & LCL & UCL \\
\hline \multicolumn{5}{|l|}{ Histidine } \\
\hline AUC $[\mathrm{nmol} / \mathrm{ml}]$ & $738.1 \pm 37.2$ & $683.9 \pm 39.8$ & 1.08 & 1.07 \\
\hline $\mathrm{C}_{\max }[\mathrm{nmol} / \mathrm{ml}]$ & $191.6 \pm 10.0$ & $190.9 \pm 7.2$ & .98 & 1.01 \\
\hline $\mathrm{T}_{\max }[\mathrm{min}]$ & $137 \pm 10$ & $52 \pm 7$ & 2.81 & 2.50 \\
\hline \multicolumn{5}{|l|}{ Isoleucine } \\
\hline AUC & $317.5 \pm 37.0$ & $424.4 \pm 31.5$ & .71 & .77 \\
\hline $\mathrm{C}_{\max }$ & $92.7 \pm 11.7$ & $144.0 \pm 5.8$ & .59 & .70 \\
\hline $\mathrm{T}_{\max }$ & $71 \pm 10$ & $73 \pm 1$ & .83 & 1.08 \\
\hline \multicolumn{5}{|l|}{ Leucine } \\
\hline AUC & $597.9 \pm 38.5$ & $769.9 \pm 50.8$ & .77 & .77 \\
\hline $\mathrm{C}_{\max }$ & $167.2 \pm 12.1$ & $240.7 \pm 12.8$ & .68 & .70 \\
\hline $\mathrm{T}_{\max }$ & $67 \pm 2$ & $85 \pm 4$ & .80 & .71 \\
\hline \multicolumn{5}{|l|}{ Lysine } \\
\hline AUC & $1,367.4 \pm 60.8$ & $1,755.0 \pm 101.5$ & .79 & .76 \\
\hline $\mathrm{C}_{\max }$ & $364.8 \pm 19.7$ & $533.6 \pm 36.1$ & .69 & .67 \\
\hline $\mathrm{T}_{\max }$ & $68 \pm 7$ & $64 \pm 3$ & 1.00 & 1.10 \\
\hline \multicolumn{5}{|l|}{ Methionine } \\
\hline AUC & $135.5 \pm 11.9$ & $163.7 \pm 17.1$ & .84 & .81 \\
\hline $\mathrm{C}_{\max }$ & $38.8 \pm 3.0$ & $54.2 \pm 6.8$ & .75 & .68 \\
\hline $\mathrm{T}_{\max }$ & $77 \pm 3$ & $63 \pm 2$ & 1.22 & 1.22 \\
\hline \multicolumn{5}{|l|}{ Phenylalanine } \\
\hline AUC & $264.8 \pm 11.9$ & $226.6 \pm 12.7$ & 1.18 & 1.16 \\
\hline $\mathrm{C}_{\max }$ & $71.3 \pm 4.0$ & $66.8 \pm 3.7$ & 1.06 & 1.07 \\
\hline $\mathrm{T}_{\max }$ & $82 \pm 11$ & $47 \pm 6$ & 1.72 & 1.74 \\
\hline
\end{tabular}




\begin{tabular}{|c|c|c|c|c|}
\hline Amino Acid & RPI & WPI & LCL & UCL \\
\hline \multicolumn{5}{|l|}{ Tryptophan } \\
\hline AUC & $556.5 \pm 40.9$ & $659.8 \pm 69.4$ & .87 & .81 \\
\hline $\mathrm{C}_{\max }$ & $152.0 \pm 11.8$ & $199.1 \pm 23.2$ & .79 & .73 \\
\hline $\mathrm{T}_{\max }$ & $93 \pm 4$ & $77 \pm 2$ & 1.12 & 1.28 \\
\hline \multicolumn{5}{|l|}{ Threonine } \\
\hline AUC & $609.7 \pm 30.1$ & $778.7 \pm 53.5$ & .79 & .76 \\
\hline $\mathrm{C}_{\max }$ & $163.6 \pm 9.1$ & $236.9 \pm 18.6$ & .70 & .67 \\
\hline $\mathrm{T}_{\max }$ & $97 \pm 6$ & $64 \pm 0$ & 1.42 & 1.60 \\
\hline \multicolumn{5}{|l|}{ Valine } \\
\hline AUC & $1,257.7 \pm 98.6$ & $1,326.0 \pm 69.8$ & .92 & .97 \\
\hline $\mathrm{C}_{\max }$ & $343.4 \pm 29.9$ & $399.2 \pm 19.4$ & .82 & .89 \\
\hline $\mathrm{T}_{\max }$ & $94 \pm 2$ & $77 \pm 4$ & 1.24 & 1.18 \\
\hline
\end{tabular}

Table 3: Pharmacokinetic Parameters of individual EAAs

\begin{tabular}{|c|c|c|c|c|}
\hline Amino Acid & Rice Protein & Whey Protein & LCL & UCL \\
\hline \multicolumn{5}{|l|}{ Alanine } \\
\hline AUC $[\mathrm{nmol} / \mathrm{ml}]$ & $830.1 \pm 68.5$ & $850.0 \pm 62.4$ & .96 & .98 \\
\hline $\mathrm{C}_{\max }[\mathrm{nmol} / \mathrm{ml}]$ & $223.8 \pm 17.8$ & $250.5 \pm 15.4$ & .87 & .90 \\
\hline $\mathrm{T}_{\max }[\min ]$ & $92 \pm 11$ & $77 \pm 4$ & 1.11 & 1.26 \\
\hline \multicolumn{5}{|l|}{ Arginine } \\
\hline AUC & $636.9 \pm 40.7$ & $524.8 \pm 43.2$ & 1.23 & 1.19 \\
\hline $\mathrm{C}_{\max }$ & $183.6 \pm 14.7$ & $168.4 \pm 11.9$ & 1.07 & 1.09 \\
\hline $\mathrm{T}_{\max }$ & $77 \pm 0$ & $56 \pm 0$ & 1.36 & 1.37 \\
\hline \multicolumn{5}{|l|}{ Asparagine } \\
\hline AUC & $606.5 \pm 44.6$ & $669.0 \pm 55.7$ & .91 & .89 \\
\hline $\mathrm{C}_{\max }$ & $161.9 \pm 14.4$ & $199.7 \pm 15.2$ & .79 & .82 \\
\hline $\mathrm{T}_{\max }$ & $113 \pm 8$ & $64 \pm 8$ & 1.88 & 1.67 \\
\hline \multicolumn{5}{|l|}{ Aspartic Acid } \\
\hline AUC & $22.0 \pm 4.1$ & $24.6 \pm 3.7$ & .85 & .91 \\
\hline $\mathrm{C}_{\max }$ & $6.2 \pm 1.2$ & $8.9 \pm 1.7$ & .69 & .70 \\
\hline $\mathrm{T}_{\max }$ & $92 \pm 17$ & $78 \pm 8$ & 1.07 & 1.26 \\
\hline \multicolumn{5}{|l|}{ Citrulline } \\
\hline AUC & $91.0 \pm 12.2$ & $98.8 \pm 16.1$ & .95 & .89 \\
\hline $\mathrm{C}_{\max }$ & $25.4 \pm 2.5$ & $32.4 \pm 6.2$ & .89 & .73 \\
\hline $\mathrm{T}_{\max }$ & $113 \pm 4$ & $116 \pm 2$ & .95 & .98 \\
\hline \multicolumn{5}{|l|}{ Cystine } \\
\hline AUC & $90.5 \pm 18.6$ & $122.7 \pm 19.5$ & .69 & .76 \\
\hline $\mathrm{C}_{\max }$ & $25.4 \pm 5.3$ & $40.1 \pm 6.1$ & .58 & .66 \\
\hline $\mathrm{T}_{\max }$ & $86 \pm 0$ & $68 \pm 4$ & 1.33 & 1.2 \\
\hline \multicolumn{5}{|l|}{ Glutamic Acid } \\
\hline AUC & $151.9 \pm 19.4$ & $182.3 \pm 56.6$ & .86 & .81 \\
\hline $\mathrm{C}_{\max }$ & $44.2 \pm 6.6$ & $66.9 \pm 6.6$ & .62 & .69 \\
\hline $\mathrm{T}_{\max }$ & $79 \pm 26$ & $53 \pm 4$ & 1.09 & 1.84 \\
\hline
\end{tabular}




\begin{tabular}{|c|c|c|c|c|}
\hline Amino Acid & Rice Protein & Whey Protein & LCL & UCL \\
\hline \multicolumn{5}{|l|}{ Glutamine } \\
\hline AUC & $1,439.9 \pm 52.3$ & $1,484.2 \pm 82.7$ & .99 & .95 \\
\hline $\mathrm{C}_{\max }$ & $373.2 \pm 15.6$ & $406.9 \pm 21.5$ & .92 & .90 \\
\hline $\mathrm{T}_{\max }$ & $70 \pm 15$ & $61 \pm 4$ & .96 & 1.32 \\
\hline \multicolumn{5}{|l|}{ Glycine } \\
\hline AUC & $833.3 \pm 53.6$ & $703.9 \pm 39.8$ & 1.17 & 1.19 \\
\hline $\mathrm{C}_{\text {max }}$ & $218.9 \pm 11.4$ & $201.8 \pm 13.8$ & 1.06 & 1.10 \\
\hline $\mathrm{T}_{\max }$ & $109 \pm 14$ & $65 \pm 29$ & 2.57 & 2.54 \\
\hline \multicolumn{5}{|l|}{ Ornithine } \\
\hline AUC & $622.7 \pm 49.6$ & $602.2 \pm 49.7$ & 1.04 & 1.03 \\
\hline $\mathrm{C}_{\max }$ & $169.1 \pm 18.5$ & $180.4 \pm 9.7$ & .88 & .99 \\
\hline $\mathrm{T}_{\max }$ & $109 \pm 1$ & $53 \pm 2$ & 2.14 & 2.00 \\
\hline \multicolumn{5}{|l|}{ Proline } \\
\hline AUC & $1,159.5 \pm 71.7$ & $1,263.2 \pm 70.1$ & .91 & .92 \\
\hline $\mathrm{C}_{\max }$ & $313.7 \pm 19.0$ & $374.8 \pm 19.1$ & .82 & .84 \\
\hline $\mathrm{T}_{\max }$ & $104 \pm 3$ & $65 \pm 0$ & 1.54 & 1.65 \\
\hline \multicolumn{5}{|l|}{ Serine } \\
\hline AUC & $618.1 \pm 43.4$ & $642.6 \pm 68.1$ & 1.00 & .93 \\
\hline $\mathrm{C}_{\max }$ & $167.6 \pm 15.70$ & $211.5 \pm 19.3$ & .79 & .79 \\
\hline $\mathrm{T}_{\max }$ & $109 \pm 7$ & $86 \pm 31$ & 2.22 & 2.10 \\
\hline \multicolumn{5}{|l|}{ Tyrosine } \\
\hline AUC & $603.2 \pm 47.0$ & $588.1 \pm 58.0$ & 1.04 & 1.00 \\
\hline $\mathrm{C}_{\max }$ & $167.1 \pm 13.2$ & $176.9 \pm 19.1$ & .97 & .91 \\
\hline $\mathrm{T}_{\max }$ & $104 \pm 16$ & $81 \pm 7$ & 1.17 & 1.42 \\
\hline
\end{tabular}

Table 4: Pharmacokinetic Parameters of individual NEAAs

\section{Discussion}

\section{Main results}

The primary findings from this investigation were that RPI showed a non-statistically significant $6.8 \%$ lower total amino acid concentration in the blood compared to WPI in resistance trained athletes. Amino acids reached peak concentrations slower after RPI administration in comparison to the fast absorbed WPI, with the exception of leucine, a key amino acid for MPS.

\section{Absorption Kinetics}

The current study demonstrated that amino acids as found in RPI are bioavailable and positively impact circulating blood levels of respective amino acids. The observed slow rise in the rate of appearance of amino acids with the RPI is consistent with other non-meat, non-dairy proteins [20,21]. While research has indicated whey protein is fast absorbing and casein protein slower absorbing, when examined by change or rise in circulating amino acids values, the data also indicates protein in general, especially leucine-containing protein will stimulate MPS to occur. At this time there is no conclusive data if a "fast" or a "slower" absorbing protein will differently affect the translation of stimulated muscle protein synthesis to new actual muscle deposition. While some studies indicate that the overall amount of MPS observed after a bolus of protein is not drastically different if the protein is a fast or a slow protein [22], some studies show that the digestion rate of proteins influences protein turnover and how amino acids support protein synthesis [23]. Recent evidence suggests that differences in the rate of absorption of different proteins can affect the amplitude and possibly duration of MPS and that this effect is possibly accentuated with resistance exercise [24]. The fast absorbed whey protein increases mixed muscle protein fractional synthetic rate at rest and after resistance exercise to a greater extent when compared to the slow absorbed casein [24]. 
Our data, would classify RPI as a medium to slow absorbing protein, which is in line with other non-meat/non-dairy proteins. In fact, we recently found that when protein supplementation was combined with a structured resistance training program, that over a 12-week period, study participants, whether randomized to receive the RPI or WPI in an isonitrogenous setting, experienced the same amount of muscle growth, revealing that the RPI was just as good as the well-established WPI at positively impacting muscle protein synthesis and overtime, actual muscle accretion [19]. While TAA for WPI reached its maximum concentration after 69 \pm $3 \mathrm{~min}$, RPI was significantly slower $(93 \pm 4 \mathrm{~min})$. On an individual amino acid basis, WPI was faster or equal for all amino acids with the excpetion of leucine, which reached $\mathrm{C}_{\max }$ faster in the RPI group. These unique absorption kinetics might be an additional explanation why 8 weeks of high-dose WPI or RPI supplementation in combination with resistance exercise training showed no difference between groups in improving body composition and exercise performance [19].

Slow absorbed casein showed a stronger satiating effect and subsequent reduced food intake compared to whey when consumed as a preload to a meal [25]. Therefore, the slower overall absorption kinetics makes RPI an interesting candidate for future satiety studies.

\section{AUC}

The digestibility (87\%) and biological value (51\%) of RPI [7] is inferior to WPI (100\%, and $100 \%$ respectively). Considering the $13 \%$ difference in digestibility or $49 \%$ difference biological value we expected to observe significance differences in TAA levels. However, RPI showed a non-significant $6.8 \%$ lower TAA concentration in the blood based on AUC in comparison to WPI. The non-significant differences in AUC corroborate the recent findings of Joy et al. that 8 weeks of high-dose WPI or RPI supplementation in combination with resistance exercise did not result in significant differences in body composition and exercise performance [19]. Using low-dose supplementation strategies, the amounts of RPI might need to be adjusted to reach optimal MPS in combination with resistance exercise in comparison to WPI to adjust for the lower amount of leucine.

\section{Strength of the study}

The cross-over design is a robust study design since the same experimental units (e.g. subjects) are given both treatments therefore eliminating inter-subject variability between subjects. In the present study there was no missing data from the attrition of participants throughout the study as each participant completed the crossover for both treatments. The intra-subject coefficient of variation for $\mathrm{C}_{\max }$ were $2.3 \%-6.2 \%($ mean $=4.4 \%)$ for the essential amino acids and $2.0 \%-10.0 \%$ (mean=5.9\%) for the non-essential amino acids. The intra-subject coefficient of variations for AUC were 3.5\%-7.3\% (mean=4.9\%) for the essential amino acids and $1.9-12.7 \%$ (mean=6.6\%) for the non-essential amino acids. The low coefficient of variation concludes that there is greater than $90 \%$ power of determining bioequivalence [26].

\section{Limitations}

As there is currently no information available on the protein absorption of RPI, we used a rather simplistic way to gather first data on the effects of RPI administration in comparison to WPI. A major limitation of this study in regards to MPS is that plasma concentrations do not directly relate to protein synthesis and breakdown. If a protein induces a higher protein synthesis, then the increase in plasma concentrations will be lower and if endogenous protein breakdown is inhibited more by a protein, the increase will be lower. The processes of ingestion, gastric emptying, proteolytic cleavage, gut transport, and splanchnic metabolism (primarily hepatic clearance) encompass 'digestion' but these processes are complex to measure with intact proteins and require multiple tracers. At this point, we can only speculate as to whether concentrations are due to faster digestion, greater uptake, or utilization. Future studies should include additional time points to reflect the different speed of appearance in the blood ( 0.5 hours, 6 and 8 hours).

\section{Conclusion}

RPI showed a non-significant $6.8 \%$ lower total amino acid concentration in the blood based on AUC when compared to WPI. Time to reach peak concentrations was slower with RPI in comparison to WPI, with the exception of leucine, a key amino acid in MPS. Future research should investigate the effects RPI on muscle protein synthesis and breakdown.

\section{Acknowledgement}

The authors would like to thank a dedicated group of subjects. The authors would like to thank Increnovo LLC, Milwaukee, WI, for funding this research.

\section{References}

1. Cermak NM, Res PT, de Groot LC, Saris WH, van Loon LJ (2012) Protein supplementation augments the adaptive response of skeletal muscle to resistance-type exercise training: a meta-analysis. Am J Clin Nutr 96: 1454-64.

2. Phillips SM, Tipton KD, Aarsland A, Wolf SE, Wolfe RR (1997) Mixed muscle protein synthesis and breakdown after resistance exercise in humans. Am J Physiol 273: E99-107. 
3. Wilson J, Wilson GJ (2006) Contemporary Issues in Protein Requirements and Consumption for Resistance Trained Athletes. J Int Soc Sports Nutr 3: 7-27.

4. Klein S, Kinney J, Jeejeebhoy K,Alpers D,Hellerstein M, et al. (1997) Nutrition support in clinical practice : review of published data and recommendations for future research directions. Clin Nutr 16: 193-218.

5. McClave SA (1995) Do peptide-based enteral formulas provide any benefit over intact protein diets? Nutrition 11: 395-7.

6. Gilani GS, Sepehr E (2003) Protein Digestibility and Quality in Products Containing Antinutritional Factors Are Adversely Affected by Old Age in Rats. Nutr J 133: 220-5.

7. Eggum BO, Hansen I, Larsen T (1989) Protein quality and digestible energy of selected foods determined in balance trials with rats. Plant Foods Hum Nutr 39: $13-21$.

8. Morita T, Kiriyama S (1993) Mass production method for rice protein isolate and nutritional evaluation. J Food Sci 58: 1393-6.

9. Fürst P, Stehle P (2004) What are the essential elements needed for the determination of amino acid requirements in humans? J Nutr 134 : 1558 S-65.

10. Phillips SM (2012) Dietary protein requirements and adaptive advantages in athletes. Br J Nutr 108: S158-67.

11. Campbell B, Kreider RB, Ziegenfuss T, La Bounty P, Roberts M, et al. (2007) International society of sports nutrition position stand: protein and exercise. J Int Soc Sports Nutr 4: 8.

12. Garlick PJ (2005) The Role of Leucine in the Regulation of Protein Metabolism. J Nutr 135: 1553S-6.

13. Zanchi NE, Nicastro H, Lancha AH (2008) Potential antiproteolytic effects of L-leucine: observations of in vitro and in vivo studies. J Nutr Metab 5: 20.

14. Norton LE, Layman DK, Bunpo P, Anthony TG, Brana DV, et al. (2009) The Leucine Content of a Complete Meal Directs Peak Activation but Not Duration of Skeletal Muscle Protein Synthesis and Mammalian Target of Rapamycin Signaling in Rats. J Nutr 139: 1103-9.

15. Wang M, Hettiarachchy NS, Qi M, Burks W, Siebenmorgen T (1999) Preparation and functional properties of rice bran protein isolate. J Agric Food Chem 47: $411-6$

16. Ni W, Tsuda Y, Takashima S, Sato H, Sato M, et al. (2003) Anti-atherogenic effect of soya and rice-protein isolate, compared with casein, in apolipoprotein E-deficient mice. Br J Nutr 90: 13-20.

17. Yu S, Fang N, Li Q, Zhang J, Luo H, et al. (2006) In vitro actions on human cancer cells and the liquid chromatography-mass spectrometry/mass spectrometry fingerprint of phytochemicals in rice protein isolate. J Agric Food Chem 54: 4482-92.

18. Ronis MJ, Badeaux J, Chen Y, Badger TM (2010) Rice protein isolate improves lipid and glucose homeostasis in rats fed high fat/high cholesterol diets. Exp Biol Med (Maywood) 235: 1102-13.

19. Joy JM, Lowery RP, Wilson JM, Purpura M, De Souza EO, et al. (2013) The effects of 8 weeks of whey or rice protein supplementation on body composition and exercise performance. Nutr J 12: 86.

20. Reidy PT, Walker DK, Dickinson JM, Gundermann DM, Drummond MJ, et al. (2013) Protein blend ingestion following resistance exercise promotes human muscle protein synthesis. J Nutr 143: 410-6.

21. Reidy PT, Walker DK, Dickinson JM, Gundermann DM, Drummond MJ, et al. (2014) Soy-dairy protein blend and whey protein ingestion after resistance exercise increases amino acid transport and transporter expression in human skeletal muscle. J Appl Physiol 116: $1353-64$.

22. Reitelseder S, Agergaard J, Doessing S, Helmark IC, Lund P, et al. (2011) Whey and casein labeled with L-[1-13C]leucine and muscle protein synthesis: effect of resistance exercise and protein ingestion. Am J Physiol Endocrinol Metab 300: E231-42.

23. Churchward-Venne TA, Burd NA, Phillips SM (2012) Nutritional regulation of muscle protein synthesis with resistance exercise: strategies to enhance anabolism. Nutr Metab (Lond) 9: 40.

24. Tang JE, Phillips SM (2009) Maximizing muscle protein anabolism: the role of protein quality. Curr Opin Clin Nutr Metab Care 12: 66-71.

25. Abou-Samra R, Keersmaekers L, Brienza D, Mukherjee R, Macé K (2011) Effect of different protein sources on satiation and short-term satiety when consumed as a starter. Nutr J. 10: 139.

26. Parr A, Gupta M, Montague TH, Hoke F (2012) Re-introduction of a novel approach to the use of stable isotopes in pharmacokinetic studies. AAPS J 14: 639-45.

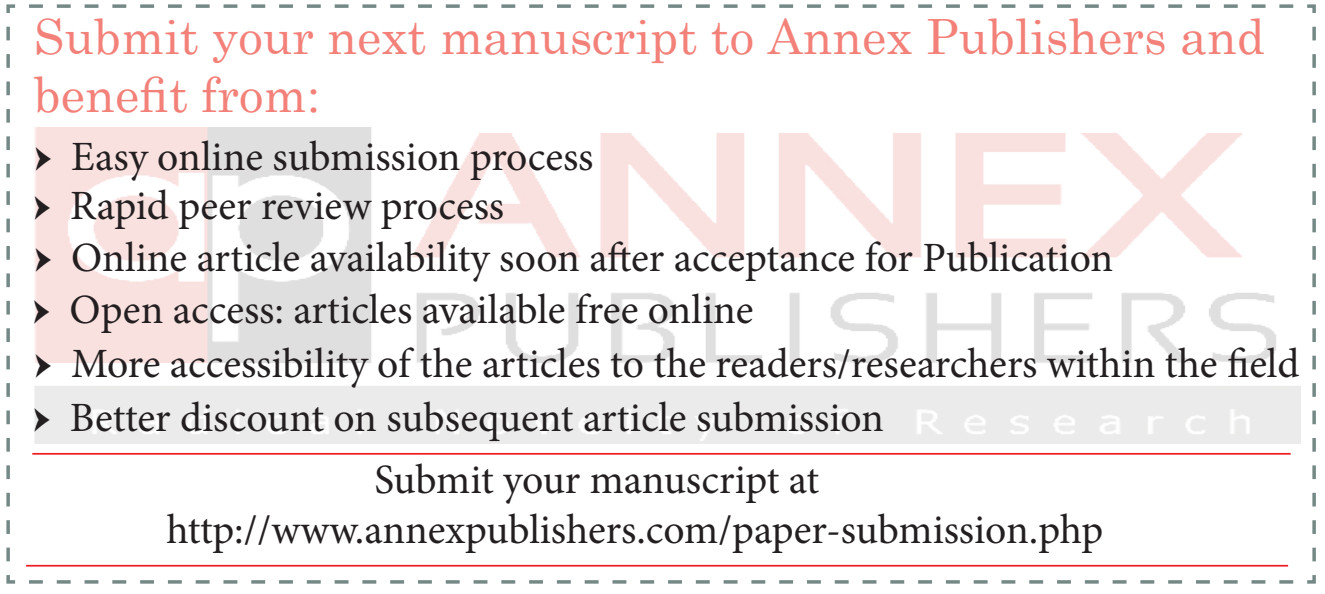

